\section{Assessment of visual function in chronic progressive external ophthalmoplegia}

\begin{abstract}
Aims To assess the visual function of patients with chronic progressive external ophthalmoplegia (CPEO) using the Visual Function Index (VF-14). To identify discriminatory questions that reflect visual disability in mitochondrial ocular myopathies. To investigate the relationship between visual impairment and the ocular parameters routinely measured in clinical practice. Methods We studied 40 CPEO patients. Each patient underwent ophthalmological assessment, including best-corrected visual acuity, ptosis measures, and fundus examination for pigmentary retinopathy, and orthoptic assessment including cover test in the primary position, assessment of diplopia, and measurement of uniocular fields of fixation using the Goldmann perimeter. Patients were interviewed by telephone by an independent observer and their visual function was assessed using the VF-14.

Results A total of 38 patients (95\%) were visually impaired. The mean VF-14 was 72 (95\% CI 66-79). Patients reported having the most difficulty with reading small print and driving at night. No significant correlation was found between the VF-14 and ocular motility parameters, ptosis, or pigmentary retinopathy. Conclusions CPEO is associated with significant visual impairment. Measures of visual disability should be included in studies of natural history and treatment of mitochondrial ocular myopathies.

Eye (2006) 20, 564-568. doi:10.1038/sj.eye.6701924; published online 27 May 2005
\end{abstract}

${ }^{1}$ Department of Ophthalmology, Royal Victoria Infirmary, Newcastle upon Tyne, UK

${ }^{2}$ Department of Neurology, The Medical School, University of Newcastle upon Tyne, UK

Correspondence: PG Griffiths, Department of Ophthalmology, Royal Victoria Infirmary, Newcastle upon Tyne NE1 4LP, UK Tel: + 440191282 5447; Fax: + 4401912825446. E-mail: p.g.griffiths@ ncl.ac.uk

Received: 23 July 2004 Accepted in revised form: 1 December 2004 Published online: 27 May 2005
Keywords: CPEO; ocular myopathy, visual function; VF-14

\section{Introduction}

Chronic progressive external ophthalmoplegia (CPEO) is a mitochondrial myopathy
CY Yu Wai Man'1,2, T Smith1', PF Chinnery², DM Turnbull ${ }^{2}$ and PG Griffiths ${ }^{1}$ characterised by ophthalmoplegia and ptosis. Mitochondrial disorders are much more common than previously thought with an overall prevalence rate of about $1 / 8500$ individuals. ${ }^{1}$ The recent 116th ENMC (European Neuromuscular Centre) conference on the treatment of mitochondrial disorders highlighted the need for a disease rating scale to study the impact of mitochondrial disorders on the activities of daily living and on quality of life issues. ${ }^{2}$ As ophthalmoplegia is one of the most common manifestations of mitochondrial cytopathies, any mitochondrial disease rating scale should include questions about visual function. $^{3}$

The Visual Function Index (VF-14) is a standardised vision-related quality-of-life instrument that has been validated in a wide range of ophthalmic conditions such as cataract surgery, ${ }^{4}$ glaucoma, ${ }^{5}$ age-related macular degeneration, ${ }^{6}$ corneal transplantation, ${ }^{7}$ retinal disease, ${ }^{8}$ myopia, ${ }^{9}$ and patients attending low-vision services. ${ }^{10}$ Here, we report the first study to assess visual function in patients suffering from a mitochondrial disorder with ocular manifestations: CPEO.

\section{Materials and methods}

\section{Participants}

We recruited 40 CPEO patients attending neuroophthalmology clinics. All the patients had positive muscle biopsies, characterised by cytochrome $c$ oxidase (COX) deficient fibres and mitochondrial DNA (mtDNA) point mutations or single/ multiple deletions. None of the patients suffered from any other ophthalmological conditions such as cataract or glaucoma. Ethical approval was sought from the local research ethics committee and informed consent was obtained from each patient. 


\section{Ophthalmological and orthoptic assessments}

All patients underwent full ophthalmic examination, including best-corrected visual acuity and fundus examination for pigmentary retinopathy. Ptosis was measured using the vertical fissure height (VFH), the levator function (LF), and the margin-reflex distance (MRD). ${ }^{11}$ We enquired about the presence of diplopia in everyday life. All orthoptic tests were carried out using the patient's corrective glasses. Cover test and prism cover test were performed for near and distance fixation in the primary position. Worth's lights were also performed at near and distance fixation, in patients with a manifest deviation, to assess suppression or diplopia. Using macular slides, the synoptophore established whether patients had fusion and stereopsis, or suppression, at their corrected angle of deviation.

Uniocular fields of fixation were also used to measure the excursion of individual extraocular muscles in their cardinal axes. ${ }^{12,13}$ This test uses the Goldmann perimeter to measure movement in the main field of muscle action. One eye is occluded and the patient is asked to follow the smallest dimmest light target possible and indicate when it disappears. The orthoptist can also objectively monitor the extent of eye movement using the Goldmann telescope. To avoid head movements during testing, the patient's head is held firmly in place by a chin rest and a head strap. Six cardinal axes, corresponding to the primary action of each extraocular muscle, are recorded in degrees on the Goldmann chart. For the right eye, these axes are lateral rectus $0^{\circ}$ superior rectus $67^{\circ}$ inferior oblique $141^{\circ}$ medial rectus $180^{\circ}$ superior oblique $216^{\circ}$, and inferior rectus $293^{\circ}$. The axes are mirrored for the left eye. The ophthalmoplegia score is the sum of excursions in all six cardinal axes.

\section{VF-14 assessment}

Patients were interviewed by telephone by an independent observer and their visual function was assessed using the VF-14. The latter is based on 14 visiondependent activities of daily living, such as reading, driving, and cooking, etc. and the patient is asked how much difficulty he/she has in performing each activity. There are five possible scores for each question: 0 (unable to do), 1 (great deal of difficulty), 2 (moderate difficulty), 3 (little difficulty), and 4 (no difficulty). A question is not included if the patient does not perform the activity for reasons other than his/her vision. An average score is then generated from all the answered questions and multiplied by 25 to give a scale ranging from 0 (worst level of function) to 100 (best level of function).

\section{Statistical analysis}

The Spearman correlation was used to test the association between VF-14 scores and ophthalmoplegia score and ptosis measures in the worse eye. The MannWhitney test was used to compare VF-14 scores between patients with and without diplopia, with and without a manifest squint, and with and without pigmentary retinopathy.

\section{Results}

\section{Patient characteristics}

Table 1 displays the patient characteristics. There were 28 females and 12 males, with a median age of 56 years (range 17-83). The majority of patients had good

Table 1 Patient characteristics

\begin{tabular}{|c|c|c|}
\hline Number of patients & & 40 \\
\hline \multicolumn{3}{|l|}{ Sex, number $(\%)$} \\
\hline Female & & $28(70)$ \\
\hline Male & & $12(30)$ \\
\hline \multicolumn{3}{|l|}{ Age (years) } \\
\hline Median (range) & & $56(17-83)$ \\
\hline Ophthalmoplegia score & Right & Left \\
\hline Mean $(95 \%$ CI) & $\begin{array}{c}108.3 \\
(89.1-127.4)\end{array}$ & $\begin{array}{c}104.4 \\
(85.3-123.5)\end{array}$ \\
\hline Range & $30-244$ & $30-270$ \\
\hline Vertical fissure height (VFH) ( $\mathrm{mm})$ & Right & Left \\
\hline Median (range) & $7(2-17)$ & $7(2-13)$ \\
\hline Levator function $(L F)(\mathrm{mm})$ & Right & Left \\
\hline Median (range) & $8(0-15)$ & $8(0-14)$ \\
\hline Margin reflex distance $(M R D)(\mathrm{mm})$ & Right & Left \\
\hline Median (range) & $1(0-3)$ & $1(0-3)$ \\
\hline \multicolumn{3}{|l|}{ Squint, number (\%) } \\
\hline Manifest & & $27(67.5)$ \\
\hline Horizontal & & $36(90)$ \\
\hline Vertical & & $12(30)$ \\
\hline Diplopia, number (\%) & & $21(52.5)$ \\
\hline Pigmentary retinopathy, number (\%) & & $9(22.5)$ \\
\hline \multicolumn{3}{|l|}{ Visual acuity in worse eye, number (\%) } \\
\hline Median & & $6 / 9$ \\
\hline $6 / 6$ or better & & $8(20)$ \\
\hline $6 / 9$ & & $13(32.5)$ \\
\hline $6 / 12$ & & $9(22.5)$ \\
\hline $6 / 18$ & & $6(15)$ \\
\hline $6 / 24$ or worse & & $4(10)$ \\
\hline \multicolumn{3}{|l|}{$V F-14$} \\
\hline Mean $(95 \%$ CI) & & $72(66-79)$ \\
\hline Range & & $5-100$ \\
\hline
\end{tabular}


best-corrected visual acuity with a median of $6 / 9$ in the worse eye. Most patients had bilateral ptosis. LF values were not applicable for the five patients who had previous frontalis suspension for their ptosis. Most patients also had fairly symmetrical opthalmoplegia. The minimum measurable amount of excursion of each extraocular muscle is $5^{\circ}$ with uniocular fields of fixation. An ophthalmoplegia score of 30 was thus arbitrarily allocated whenever it was too small to be measured exactly. Of the 40 patients, 13 were binocular and 27 had a manifest squint. Of those 27 patients with a manifest squint, 21 had diplopia and six had suppression. In all, 36 patients (34 with exodeviation and two with esodeviation) had a horizontal deviation and 12 of these patients also had an associated vertical deviation. Nine patients had pigmentary retinopathy.

\section{Visual impairment}

Figure 1 shows the VF-14 distribution in CPEO patients. A total of 38 patients (95\%) reported some degree of

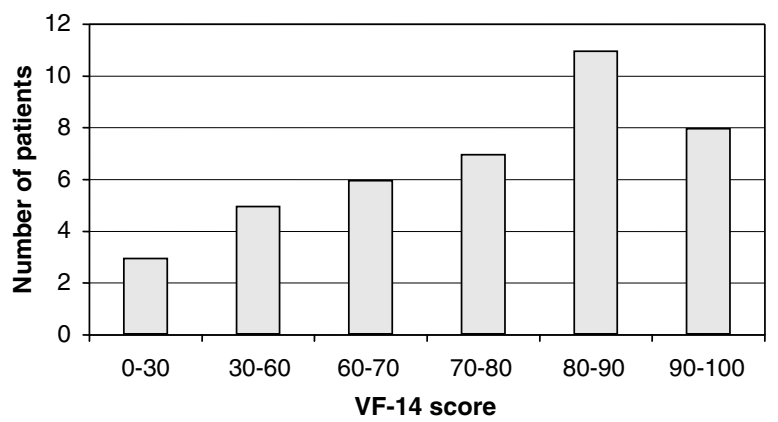

Figure 1 VF-14 distribution in CPEO patients. visual impairment while only two patients (5\%) reported the best level of function with a VF-14 of 100. There was a wide range of VF-14 reported from 5 to 100 and the mean VF-14 was 72 (95\% CI 66-79).

Table 2 displays the VF-14 items ranked by order of impact on the patients. All the patients found all the questions applicable except for those relating to driving and sports involvement. A total of 16 patients had never learned to drive or did not possess a car while six patients did not practise any sports for reasons other than their vision. CPEO patients reported having the most difficulty with reading small print and driving at night and the least difficulty with reading large print and cooking.

\section{Relationship between the VF-14 and ocular parameters}

We did not find any significant correlation between the VF-14 and the ophthalmoplegia score (Spearman correlation $=0.309, P=0.052$ ). No significant correlation was also found between the VF-14 and ptosis measures: VFH (Spearman correlation $=0.269, P=0.093$ ), LF (Spearman correlation $=-0.018, P=0.910$ ), and MRD (Spearman correlation $=0.356, P=0.036$ ).

We also found no significant differences in VF-14 scores between patients with and without diplopia $(P=0.565)$, with and without a manifest squint $(P=0.450)$, and with and without pigmentary retinopathy $(P=0.436)$.

\section{Discussion}

The VF-14 is a well-validated vision-related quality-oflife scale with high internal consistency, ${ }^{14}$ strong testretest reliability, ${ }^{15}$ and high responsiveness to change. ${ }^{16,17}$

Table 2 VF-14 question responses ranked by the percentage of patients reporting some difficulty

\begin{tabular}{|c|c|c|c|c|c|}
\hline \multirow[t]{2}{*}{ Question (No. of patients applicable) } & \multicolumn{5}{|c|}{ Extent of difficulty (\%) } \\
\hline & None & Little & Moderate & Great deal & Unable to do \\
\hline Driving at night (24) & 12.5 & 33.3 & 33.3 & 12.5 & 8.4 \\
\hline Reading small print (40) & 27.5 & 12.5 & 35 & 15 & 10 \\
\hline Reading normal print (40) & 30 & 27.5 & 22.5 & 17.5 & 2.5 \\
\hline Sports involvement (34) & 35.3 & 14.7 & 26.5 & 20.6 & 2.9 \\
\hline Reading traffic/shop signs (40) & 37.5 & 17.5 & 32.5 & 7.5 & 5 \\
\hline Doing fine handwork (40) & 37.5 & 20 & 20 & 20 & 2.5 \\
\hline Seeing steps, stairs or curbs (40) & 40 & 15 & 32.5 & 10 & 2.5 \\
\hline Watching television $(40)$ & 42.5 & 27.5 & 22.5 & 5 & 2.5 \\
\hline Driving during the day (24) & 54.2 & 12.5 & 16.7 & 8.3 & 8.3 \\
\hline Playing table games $(40)$ & 57.5 & 12.5 & 20 & 7.5 & 2.5 \\
\hline Writing cheques or completing forms (40) & 62.5 & 12.5 & 20 & 0 & 5 \\
\hline Recognising people at close distances (40) & 65 & 20 & 10 & 2.5 & 2.5 \\
\hline Cooking (40) & 67.5 & 17.5 & 12.5 & 0 & 2.5 \\
\hline Reading large print (40) & 67.5 & 12.5 & 10 & 7.5 & 2.5 \\
\hline
\end{tabular}


The overall self-rating of the amount of difficulty patients have with their vision has also been shown to be more strongly correlated with the VF-14 than with measures of visual acuity or generic health related quality-of-life scales such as the SF-36. ${ }^{8,17-19}$ Moreover, the succinct format and ease of administration of the VF-14 also make it a popular choice.

Since the ophthalmoplegia in CPEO is relatively symmetrical $^{13}$ and diplopia is said to be uncommon, there is a perception that patients with CPEO are not greatly visually handicapped. However, recent work has shown that diplopia in CPEO is more common than previously thought. ${ }^{13}$ Furthermore, the associated ptosis in CPEO patients may further increase their levels of visual impairment. A rating scale of visual function is thus required as visual acuity alone may not reflect levels of visual handicap.

Our data show that the majority of CPEO patients are visually impaired. We also found that the level of visual impairment experienced by CPEO patients is significant when compared to that reported in common ophthalmic conditions such as cataract, ${ }^{4}$ glaucoma, ${ }^{5}$ and age-related macular degeneration (Table 3$)^{6}$

We were surprised that there were no significant differences in VF-14 scores between patients with and without diplopia. This might reflect the small sample size, given the relative rarity of the condition, or the fact that diplopia was intermittent or controlled with prisms in most cases. We also did not find any significant correlation between the VF-14 and the ocular motility parameters, ptosis measures, or pigmentary retinopathy.

We are aware that there might be other factors that we have not measured, which might be relevant in the assessment of visual function in CPEO, particularly orbicularis function. However, quantitative measures of orbicularis function are not readily available at present.

Table 3 Mean VF-14 in CPEO and other ophthalmic conditions

\begin{tabular}{lr}
\hline Ophthalmic condition & Mean VF-14 \\
\hline Cataract surgery (4) & 73 \\
Pre-operative & 91 \\
Post-operative (4 months) & 89 \\
Age-related macular degeneration (6) & 84 \\
Retinal disease (eg diabetic retinopathy, retinal & \\
$\quad$ detachment) (8) & 84 \\
High myopia (9) & 80 \\
Glaucoma (5) & 77 \\
Corneal transplantation (at least 1 year post-op) (7) & 72 \\
CPEO & 41 \\
Low vision services (10) &
\end{tabular}

It might be argued that the presence of ptosis obscures diplopia thus masking the handicap induced by the ptotic eyelid. However, all of our patients with diplopia reported the problem in everyday life rather than on orthoptic testing with the eyelids propped up, so it is unlikely that this is the case.

CPEO patients reported having the most difficulty with reading small print and driving at night. These two activities might be particularly difficult in CPEO because of the difficulty engendered in rapid scanning eye movements to view objects on the road or on the printed page. As conventional clinical tests do not reflect visual disability, these two questions would be useful indicators of visual impairment in studies of natural history and treatment of mitochondrial ocular myopathies, provided other causes of image degradation such as cataracts have been excluded.

Our study is also relevant to the proposed mitochondrial disease rating scale. ${ }^{2}$ The main aim of this rating scale would be to focus on the impact of mitochondrial disease on the activities of daily living and on quality-of-life issues rather than physiological or pathological measurements. From our data, reading small print and driving at night would be most sensitive in screening for visual impairment if included in the rating scale. As many patients with mitochondrial disease also have generalised myopathy, questions about activities that are dependent on physical ability, such as sport involvement, should be avoided in the visual rating scale. In practice, it is hard to separate difficulty with sporting activities due to limited mobility and stamina with that due to poor vision.

\section{References}

1 Chinnery PF, Turnbull DM. Epidemiology and treatment of mitochondrial disorders. Am J Med Genet 2001; 106(1): 94-101.

2 Chinnery PF, Bindoff LA. 116th ENMC international workshop: the treatment of mitochondrial disorders, 14th-16th March 2003, Naarden, The Netherlands. Neuromuscular Disorders 2003; 13(9): 757-764.

3 Petty RK, Harding AE, Morgan-Hughes JA. The clinical features of mitochondrial myopathy. Brain 1986; 109(Part 5): 915-938.

4 Norregaard JC, Bernth-Petersen P, Alonso J, Andersen TF, Anderson GF. Visual functional outcomes of cataract surgery in the United States, Canada, Denmark, and Spain: report of the International Cataract Surgery Outcomes Study. J Cataract Refract Surg 2003; 29(11): 2135-2142.

5 Gutierrez P, Wilson MR, Johnson C, Gordon M, Cioffi GA, Ritch $\mathrm{R}$ et al. Influence of glaucomatous visual field loss on health-related quality of life. Arch Ophthalmol 1997; 115(6): 777-784.

6 Mackenzie PJ, Chang TS, Scott IU, Linder M, Hay D, Feuer WJ et al. Assessment of vision-related function in patients 
with age-related macular degeneration. Ophthalmol 2002; 109(4): 720-729.

7 Musch DC, Farjo AA, Meyer RF, Waldo MN, Janz NK. Assessment of health-related quality of life after corneal transplantation. Am J Ophthalmol 1997; 124(1): 1-8.

8 Linder M, Chang TS, Scott IU, Hay D, Chambers K, Sibley LM et al. Validity of the visual function index (VF-14) in patients with retinal disease. Arch Ophthalmol 1999; 117(12): 1611-1616.

9 Rose K, Harper R, Tromans C, Waterman C, Goldberg D, Haggerty $\mathrm{C}$ et al. Quality of life in myopia. Br J Ophthalmol 2000; 84(9): 1031-1034.

10 Scott IU, Smiddy WE, Schiffman J, Feuer WJ, Pappas CJ. Quality of life of low-vision patients and the impact of low-vision services. Am J Ophthalmol 1999; 128(1): 54-62.

11 Tyers AG, Collin JRO In: Colour Atlas of Ophthalmic Plastic Surgery. Churchill Livingstone: New York, 1995, pp 46-47.

12 Haggerty H, Richardson S, Mitchel K, Dickinson A. A modified method for the reliable assessment of uniocular fields of fixation. In: Transactions of the European Strabismological Association, 27th Annual meeting, Florence, 2001.

13 Richardson C, Smith T, Schaefer A, Turnbull D, Griffiths P. Ocular motility findings in chronic progressive external ophthalmoplegia. Eye 2005; 19: 258-263.
14 Steinberg EP, Tielsch JM, Schein OD, Javitt JC, Sharkey P, Cassard SD et al. The VF-14. An index of functional impairment in patients with cataract. Arch Ophthalmol 1994; 112(5): 630-638.

15 Steinberg EP, Tielsch JM, Schein OD, Javitt JC, Sharkey P, Cassard SD et al. National study of cataract surgery outcomes. Variation in 4-month postoperative outcomes as reflected in multiple outcome measures [comment]. Ophthalmol 1994; 101(6): 1131-1140; discussion 1140-1141.

16 Alonso J, Espallargues M, Andersen TF, Cassard SD, Dunn $\mathrm{E}$, Bernth-Petersen $\mathrm{P}$ et al. International applicability of the VF-14. An index of visual function in patients with cataracts. Ophthalmology 1997; 104(5): 799-807.

17 Cassard SD, Patrick DL, Damiano AM, Legro MW, Tielsch $\mathrm{JM}$, Diener-West $\mathrm{M}$ et al. Reproducibility and responsiveness of the VF-14. An index of functional impairment in patients with cataracts. Arch Ophthalmol 1995; 113(12): 1508-1513.

18 Lee JE, Fos PJ, Zuniga MA, Kastl PR, Sung JH. Assessing health-related quality of life in cataract patients: the relationship between utility and health-related quality of life measurement. Quality of Life Res 2000; 9(10): 1127-1135.

19 Parrish 2nd RK. Visual impairment, visual functioning, and quality of life assessments in patients with glaucoma. Trans Am Ophthalmol Society 1996; 94: 919-1028. 